\title{
Cognitive Artifacts for Geometric Reasoning
}

\author{
Mateusz Hohol ${ }^{1,2}$ (D) Marcin Miłkowski²
}

Published online: 4 May 2019

(c) The Author(s) 2019

\begin{abstract}
In this paper, we focus on the development of geometric cognition. We argue that to understand how geometric cognition has been constituted, one must appreciate not only individual cognitive factors, such as phylogenetically ancient and ontogenetically early core cognitive systems, but also the social history of the spread and use of cognitive artifacts. In particular, we show that the development of Greek mathematics, enshrined in Euclid's Elements, was driven by the use of two tightly intertwined cognitive artifacts: the use of lettered diagrams; and the creation of linguistic formulae (namely non-compositional fixed strings of words used repetitively within authors and between them). Together, these artifacts formed the professional language of geometry. In this respect, the case of Greek geometry clearly shows that explanations of geometric reasoning have to go beyond the confines of methodological individualism to account for how the distributed practice of artifact use has stabilized over time. This practice, as we suggest, has also contributed heavily to the understanding of what mathematical proof is; classically, it has been assumed that proofs are not merely deductively correct but also remain invariant over various individuals sharing the same cognitive practice. Cognitive artifacts in Greek geometry constrained the repertoire of admissible inferential operations, which made these proofs inter-subjectively testable and compelling. By focusing on the cognitive operations on artifacts, we also stress that mental mechanisms that contribute to these operations are still poorly understood, in contrast to those mechanisms which drive symbolic logical inference.
\end{abstract}

Keywords Cognitive artifacts - Diagrammatic inference - Epistemology of mathematics · Geometric cognition · Mathematical enculturation

Mateusz Hohol

mateusz.hohol@uj.edu.pl

1 Copernicus Center for Interdisciplinary Studies, Jagiellonian University, Kopernika 27, 31-501 Cracow, Poland

2 Institute of Philosophy and Sociology, Polish Academy of Sciences, Nowy Świat 72, 00-330 Warsaw, Poland 


\section{Introduction}

Cognitive science increasingly focuses on the role of cognitive artifacts in cognitive practices. The notion of the cognitive artifact has been defined by Donald Norman (1991). These artifacts are entities that "maintain, display, or operate upon information in order to serve a representational function and that affect human cognitive performance" (p. 17). This focus on artifacts goes hand in hand with the growing consensus that even highly intellectual endeavors depend on structuring the cognitive niche by cognitive agents (Clark 2006). Mathematical practice is a prime example of such practice. Consequently, the stress on the role of artifacts leads to rethinking the epistemology of mathematics. The typical view in cognitive science is that mathematical cognition should be studied as a purely individual achievement. In contrast, we point out that mathematical justificatory practices may be understood in terms of repeatable public procedures that rely on the capacities of cognitive agents to jointly construct, explore and reconfigure representational tokens (Tylén et al. 2014). In other words, mathematical practice is shared by many individuals who can publicly use the same artifacts to achieve the same results, for example prove theorems by manipulating diagrams. Mathematical cognition, and cognition in general, is therefore no longer understood in terms of solely individual achievements (Goldstone and Janssen 2005; Gureckis and Goldstone 2006; R. A. Wilson 2004). ${ }^{1}$

In this paper, we argue that geometric cognition relies on cognitive artifacts. While this claim follows from the fairly bland observation that such artifacts are involved in any shared cognitive practice, we will argue that it has a non-trivial consequence for the scientific study of geometric cognition. While the extant studies of geometry in cognitive science do mention the role of cognitive tools or artifacts, as we will show, they remain crucially incomplete in one regard. To fully understand any system of representation, one has to account for the available operations on these representations (Sloman 1978). This is because depending on the operations, different cognitive results using the same representations could be achieved. The problem, however, is that we still do not know the mechanisms of geometric reasoning. In other words, cognitive operations on geometric representations that allow us to draw inferences from manipulations of cognitive artifacts in geometry remain poorly understood. Furthermore, we claim that the necessity and generality of the geometric proof rely on the distributed practice that includes dedicated cognitive artifacts and cannot be reduced to properties of individual cognitive capacities. We will also defend the claim that cognitive artifacts constrain the admissible deductive operations, thus constituting the necessity of the proof.

Studies on the cognitive processing of numbers have been conducted since the 1960s (Moyer and Landauer 1967), and in recent decades, a new research field of cognitive science, known as numerical cognition, has been established (Cohen Kadosh and Dowker 2015; LeFevre 2016). Each year, a number of experimental reports-concerning the impact of both domain-specific (Cipora et al. 2016; Feigenson et al. 2004) and domaingeneral factors (Hohol et al. 2017a; Wołoszyn and Hohol 2017) - is published in numerous scientific journals. Furthermore, the most current knowledge on number processing has been synthesized in several book monographs, whose authors and contributors use

\footnotetext{
1 Typical research conducted in the field of cognitive science of mathematics focuses, as Núñez and Lakoff (2005) notice, on psychological and neuroscientific issues involved in the mathematically relevant behavior of an individual; thus, the research field is elucidated at the level of a person or individual's brain.
} 
differing, and — at least to some extent-competitive, theoretical perspectives (Adams et al. 2017; Dehaene 2011; Henik 2016; Lakoff and Núñez 2000).

By contrast, Euclidean geometry - one of the key areas of mathematics - has rarely been studied by cognitive scientists who are interested in the explanation of mathematical skills. Geometry is essentially absent in fundamental book monographs in cognitive science of mathematics (to mention at least the publications cited above) ${ }^{2}$ Admittedly, studies relevant to cognitive foundations of geometry so far have focused on, inter alia, children's construction of Euclidean intuitions and geometric concepts (Piaget et al. 1960), development of geometric skills in terms of their transition to higher levels (van Hiele 1986), ways of improving the acquisition of these skills in the educational process (Battista 2007; Clements and Battista 1990), human comprehension of geometric language (Amalric et al. 2017), as well as neural and cognitive underpinnings of the processing of geometric properties of both two-dimensional shapes (Izard and Spelke 2009; Zoccolan et al. 2009) and three-dimensional spatial layouts (Cheng 1986; Dillon et al. 2017) by both human and non-human animals (Derdikman and Moser 2010; Thinus-Blanc et al. 2010; Tomassi et al. 2012). Compared to numerical cognition, scientists interested in cognitive foundations of geometry have created, however, few theoretical perspectives of the integration of distributed findings on geometric cognition's various dimensions (i.e., developmental, educational, ethologic, neuroscientific). The theory of core cognitive systems for geometry proposed-and still being developed-by Elizabeth Spelke and her collaborators is a creditable exception in this matter (Carey and Spelke 1996; Dillon et al. 2013; Spelke and Lee 2012; Spelke et al. 2010). These studies, however, largely ignore the role of enculturation in the shaping of geometric cognition, and in particular the role of cognitive artifacts.

The paper proceeds as follows. First, we briefly introduce desiderata for the study of geometric cognition. Next, we review the research on geometry that is confined to the evolutionary timescales. In particular, we focus on Spelke and collaborators' account of the development of geometric cognition. We also specify the role of artifacts in shaping the generality of geometric concepts in their account. This description shows that enculturation is an indispensable feature of a full explanation of mechanisms underlying geometric reasoning in human beings. However, we stress that this part of the account of geometric cognition is sketchy and unclear. In the third section, we turn to the case study in the history of geometry, by analyzing the structure of a well-known proof in Euclid's Elements, i.e., Proposition 1 of Book 1. We show how lettered diagrams and linguistic repeatable formulae intertwine, which is then analyzed in more detail in the next section. The fourth section focuses on inference operations: While the constructed proof is a clear example of a deductive inference, it remains unclear what operations underlie this deduction and how students of geometry are capable of generating the sequence of operations that lead to the proof. The geometric proof itself, as an inter-subjectively usable artifact, makes use of these two structures. This use, as we show in the ensuing section, has become the foundation for the necessity and generality of geometric deductive proofs. In the penultimate section, we argue against Netz's (2003) claim that lettered diagrams and technical language can substitute for the ontology of mathematics. We show that these artifacts contribute to of generality and necessity. These are epistemic virtues or beneficial properties of mathematical knowledge. However, the fact that generality and necessity are attained thanks to the use of

\footnotetext{
${ }^{2}$ Furthermore, a simple keyword search on "geometric cognition" in Google Scholar-without setting the scope of years-found only about 100 hits (end of December 2018). For a query "cognitive science of geometry," the result was smaller, giving only two hits.
} 
artifacts does not determine what mathematical knowledge is really about. In other words, the use of artifacts does not settle ontological issues in mathematics at all.

In conclusion, the historical insight into the development of proofs in geometry provided in this paper shows that mathematical epistemology of the proof is deeply enculturated, and relies on joint practices on cognitive artifacts. Consequently, it undermines purely individualist accounts of mathematical cognition, typically espoused by mathematical Platonists, such as Roger Penrose (1996). Nevertheless, the focus on the cultural scaffolding of mathematical practice does not justify radical social constructivist claims that mathematical theorems are only valid with respect to some cultural backgrounds (Burton 1995). On the contrary, it is the cultural practice of using cognitive artifacts that licenses the inter-subjective and intercultural validity of mathematics. We argue that mathematics could not remain as stable a cognitive practice as it is, were it not for the widespread practice of constraining reasoning patterns by external cognitive artifacts. In other words, we claim that the study of the enculturation of mathematical cognition can be informative for the epistemology of mathematics and not just for its historical development.

\section{Desiderata for the Study of Geometric Cognition}

The adequate account of geometric cognition, as we claim, should fulfill, at least, the following desiderata about geometric representations, concepts and epistemic properties of geometry:

(D1) The account should recognize "hardwired," or evolutionarily early, cognitive abilities that are necessary to engage in Euclidean geometry, such as natural sensitivity to distance (proximal-distal), sense (left-right) and angle, and thus explain where geometric cognition come from.

(D2) The account should describe how these "hardwired" cognitive prerequisites are combined during ontogeny into a system of abstract geometric representations.

(D3) The account should show how Euclidean proofs gain their compelling power, or what makes them necessarily true.

(D4) The account should recognize how each Euclidean proof establishes general results despite the fact that it begins with concrete cases.

(D5) The account should elucidate the inference operations involved in geometric reasoning.

The desiderata (D2), (D3), and (D4) can be fulfilled, as we argue, only by focusing on the role of cognitive artifacts in processes of geometric enculturation on various timescales. (D5) requires also that operations on these artifacts be elucidated. Although the enculturation of numerical cognition is a well-recognized topic, and recently it has been discussed by Núñez (2017a, b) and Menary (2015), no one, to the best of our knowledge, has yet systematically analyzed the role of cognitive artifacts in the scientifically informed epistemology of geometry. Current theories of geometric cognition offer, moreover, at best sketchy accounts of operations involved in geometric reasoning. However, such theories are crucial to understanding how geometric reasoning works because reasoning requires two crucial components: (1) well-formed geometric representations and (2) inference operations. For example, to perform logical inference in classical propositional logic, one relies both on well-formed formulae composed of brackets, parentheses, propositional variables, logical 
connectives (i.e., operators), and on inference operations, such as double negation elimination, modus ponens, or disjunctive syllogism. These are syntactic transformation rules that allow one to infer a conclusion from a list of premises. However, even though we perfectly know what well-formed geometric representations look like, appropriate syntactic transform rules for geometry are not clearly defined nor automatically well understood.

But the set of all admissible inference operations is not everything that proofs require. Just like the sequence of inference steps that constitutes a proof in symbolic logic is sometimes non-trivial to find, it is also sometimes difficult to come up with an appropriate sequence of steps to produce proof in geometry. In other words, even if one knows all the inference operations admissible in geometric reasoning, one could still fail to provide a proof of a theorem. Unfortunately, it remains unclear how people produce sequences of operations as proofs. Therefore, we will stress the need to deal with (D5) in future research, both related to simple inference steps and to procedures aimed to generate an appropriate sequence of steps (usually supported with additional constructions on a diagram).

Core systems of geometric cognition, as studied by Spelke et al. (2010), are understood on the evolutionary timescale. Although their phylogeny is not culturally mediated, they are transformed during individual development into a new human system of geometric representations. Therefore, this account satisfies (D1) and (D2). However, they do not suffice for the full generality of geometric proofs. The generality of geometric concepts is explained by Spelke and colleagues on the developmental, or ontogenetic, timescale by recourse to the acquaintance with scale-models and maps, that allows human children to overcome the limits of core systems. As they show, these artifacts are an important additional factor that goes beyond the largely innate geometric capacities of human children and other animals. It is however unclear that mere pointing to artifacts in their account is sufficient to satisfy (D4), as we show in detail below. Moreover, the actual history of mathematics demonstrates, as we claim, that the idea of an inter-subjectively replicable mathematical proof has become viable only owing to a set of shared cognitive artifacts. Note that this insight is not offered by the research on the development at the evolutionary or ontogenetic timescales, which thus fails to satisfy (D3).

To understand how geometric cognition has been constituted, as we argue, we need to appreciate not only individual cognitive factors, such as phylogenetically ancient and ontogenetically early core systems of geometric knowledge, but also the social history of the spread and use of cognitive artifacts. In this respect, the case of Greek geometry, as epitomized in Euclid's Elements, clearly shows that cognitive explanations of geometric reasoning have to go beyond the confines of the study of individuals, as engaged in mathematical tasks, to account for the stabilization of distributed practice of artifact use over time. ${ }^{3}$ This practice, as we suggest, has also contributed heavily to the understanding of mathematical proof. Classically, it has been assumed that proofs are not merely deductively correct, but also remain invariant among various individuals sharing the same cognitive practice. Only by accounting for the role of cognitive artifacts and operations on these artifacts can we satisfy the two crucial desiderata, namely (D3) and (D4).

\footnotetext{
${ }^{3}$ However, the practice itself has evolved over time. Our focus on Euclid's Elements is motivated not only by the prominent role of artifacts in mathematical practice. The study of geometry and mathematics in Europe has also been shaped by Elements, whose understanding has also changed (Malet 2012; Scriba and Schreiber 2015). We do not mean to suggest, for example, that the original understanding of necessity and generality in Greek geometry was retained in the ensuing centuries, while Euclid's masterpiece has remained the blueprint of deductive presentation's mathematical perfection.
} 
In particular, we will claim that the development of Greek mathematics, enshrined in Euclid's Elements and other treatises such as Archimedes' Spiral lines or Pappus' Collectio, was driven by the use of several tightly intertwined cognitive artifacts; one was the use of lettered diagrams, and another the creation of the linguistic formulae, namely noncompositional fixed strings of words, used repetitively by authors and between them, which formed professional language of geometry. Together, as Reviel Netz (2003) pointed out, diagrams and formulae have contributed to making geometric practice both reliable and learnable. Lettered diagrams, on the one hand, contribute to the specification of objects. They are full-blooded components of geometric arguments, and allow mathematicians to study the universe of geometric discourse. Linguistic formulae, on the other hand, serve as building-blocks for arguments. They make Greek geometry resemble the structured system of recurrences, and transfer necessity from starting-points to further steps of an argument, making geometric proofs necessary. While Netz has clearly underlined the intertwining of lettered diagrams and linguistic formulae, his cognitive history of geometry fails to account for inferential operations on cognitive artifacts, which allowed Greek adepts of geometry to perform their proofs. It is unclear, in particular, what are the syntactic rules for transforming diagrams to arrive at valid conclusions in geometry. For this reason, Netz's cognitive history of geometry does not fully satisfy (D5), even if it is consistent with the account of cognitive artifacts defended later in this paper.

\section{Individualistic Cognition of Geometry and Beyond}

In their influential paper, Carey and Spelke (1996) pointed to the analogy between cognitive capacities of animals and the initial equipment of human children. Moreover, they claimed that the cognitive apparatus of human adults includes a small number of domainspecific core systems that manifest their action at the earliest ages. These systems are hardwired, in the sense that they appear too early in life to be an outcome of socialization, linguistically mediated interactions with parents and other people, or even associative learning. Such systems, as Spelke and Kinzler (2007) summarize,

...serve to represent inanimate objects and their mechanical interactions, agents and their goal-directed actions, sets and their numerical relationships of ordering, addition and subtraction, and places in the spatial layout and their geometric relationships. Each system centers on a set of principles that serves to individuate the entities in its domain and to support inferences about the entities' behavior. Each system, moreover, is characterized by a set of signature limits that allow investigators to identify the system across tasks, ages, species, and human cultures (p. 89).

Owing to their domain-specificity, limitation, and innate nature, core cognitive systems seem, at least to some extent, similar to cognitive modules (Fodor 1983). ${ }^{4}$ Beyond domain-specificity, signature limits, and nativism, Horst (2016) enumerates additional module-like characteristics of core systems. Such systems can be found in everyone regardless of age (typicality); analogs of human core systems can be found (at least) in our close evolutionary relatives (interspecific similarity). Each system is sensitive only to particular

\footnotetext{
4 Note that the idea of a "geometric module" underlying spatial navigation was first introduced by Cheng (1986) and Gallistel (1990) over three decades ago, to be later criticized by its own founding fathers (Cheng and Newcombe 2005; Cheng et al. 2013; see also Hohol et al. 2017b).
} 
kinds of information, and it generates specified expectations, moreover, the subject matter of each system is encoded in a particular way (proprietariness), and finally, each system has its own characteristic pattern of breakdown, which indirectly indicates another feature: localization.

Spelke and collaborators (2010) claim that geometric cognition, as a whole, "is founded on at least two evolutionarily ancient, early developing, and cross-culturally universal cognitive systems that capture abstract information about the shape of the surrounding world" (p. 865). Thus, they propose that the explanation of hardwired geometric capacities, in their whole range, requires taking into account at least two distinct core systems, i.e., a system of layout geometry, supporting spatial navigation and applying to large-scale environmental layouts, and a system of object geometry, which supports the recognition of small-scale visual forms and manipulable objects.

The former represents spatial relationships in an abstract way-the representation of space is formed independently of color, luminance, or texture of the environment (Cheng 1986; Hermer and Spelke 1994). This system encodes two basic Euclidean properties: egocentric distance (proximal-distal) and sense (left-right). It provides the metric frame, which enables inferences about the position of the animal, and the locations of objects and places in environments. The scope of this core system, however, is limited because of its insensitivity to angles - the third basic Euclidean property. Furthermore, two-dimensional visual forms, i.e., surface markings, remain out of its reach. Thus, as Spelke and collaborators (2010) note, the core system of layout geometry cannot be understood as the complete foundation of geometric cognition.

The latter-the system of object geometry-encodes shapes of two-dimensional forms and manipulable (or movable) three-dimensional objects. Since the encoding is independent of variations in features like the orientation of objects, their substance, and their texture, geometric representations formed by this system are abstract as well. This system reveals sensitivity to Euclidean properties of angle - in contrast to the core system of layout geometry-and length, but not sense (left-right). Thus, it is not suitable for representing the geometry of the large-scale navigable spatial layouts. Furthermore, owing to the limitations of this system, children (Izard and Spelke 2009) and uneducated adults (Dehaene et al. 2006) fail to perform correctly in experimental trials that require differentiating a target shape from its mirror image. In the case of the core system for object geometry, Spelke and colleagues (2010) also claim that it cannot account for entire geometric cognition.

Although the theory of the two core systems of geometry is based primarily on the results of behavioral studies (Dillon et al. 2013; Gouteux and Spelke 2001; Hermer and Spelke 1994; Izard and Spelke 2009; Lee and Spelke 2008; Wang and Spelke 2002), a dissociation between the two domains of spatial processing is, as Spelke and colleagues (2010) note, well-grounded also in neuroscientific and neuropsychological data. It includes results of neuroimaging and lesion studies on human adults, as well as psychophysiological research on animals. It is known, on the one hand, that the hippocampus and the surrounding cortex are involved in the processing of geometric information in the service of navigation in large-scale environments (E. I. Moser et al. 2008; E. I. Moser et al. 2017; O'Keffe and Nadel 1978). More recent studies with human participants show also that sense and distance during scene perception are encoded by the occipital place area (Dilks et al. 2013) and the retrosplenial complex (Maguire 2001; Persichetti and Dilks 2016). Brain structures involved in the recognition of small two-dimensional visual forms and three-dimensional manipulable objects include the lateral occipital cortex, occipitotemporal sulcus, and fusiform gyrus, creating together a so-called lateral occipital complex (Grill-Spector et al. 2008; Kourtzi and Kanwisher 2001). 
Furthermore, the claim that a similar dissociation in the processing of places (underlying navigation) and objects (underlying recognition) also takes place at the level of visual pathways, was put forward in the 1980s (Mishkin et al. 1983). According to this view, two separate cortical pathways in the primate brain are involved in object recognition (ventral stream or "what?" system) and locating them on the surroundings (dorsal stream or "where?" system). The results of neuropsychological studies on lesioned patients support this claim. Depending on the brain area that has been damaged, patients show differentiated problems with spatial processing (Milner and Goodale 2006). Thus, Spelke's theory of two core systems for geometry converges with Milner and Goodale's theory of two visual systems.

The claim about the division in encoding "what?" and "where?" is also supported by results from cognitive linguistics. Landau and Jackendoff (1993) claim that evidence from object nouns and spatial prepositions in English, and in other languages, indicate that the geometric richness in representing objects and places differs significantly. On the one hand, when an object is named as belonging to a category, its geometric properties of shape and angle are represented in contrast to its distance and sense. On the other hand, when the same object occurs as a figure (or as located object), or a reference object (or ground), in a locational expression, primarily metric properties are represented, but properties of shape and angle are neglected. As Landau and Jackendoff (ibid.) conclude, "differences in how objects and places are represented may be correlated with a property of neurological design: a separation of spatial cognitive systems into what and where" (p. 236).

As we have already mentioned, Spelke and colleagues (2010) claim that none of the core systems can explain all manifestations of geometric cognition, because each one is limited to processing only some geometric properties. It is however unclear whether any of the core systems posited in their account can explain geometric reasoning involved, for example, in practical problem solving, such as shaping of hooks by crows (Weir et al. 2002). As such, they do not address (D5). Moreover, none of them can explain the human practice with Euclidean geometry. In their opinion, the entry into the world of Euclidean geometry requires a further "culturally-driven" developmental step that is not available for non-human animals. As Spelke and collaborators (ibid.) say, "children go beyond these limits and construct a new system of geometric representation that is more complete and general, by combining productively the representations delivered by these two systems." (p. 865) According to these authors, this developmental step is made thanks to the experience with artifacts, such as spatial language, diagrams and maps (Landau and Lakusta 2009; Spelke 2003; Spelke et al. 2011) in the following ways:

First, through their experience with pictures, scale models, and maps, children may begin to view large-scale layouts not only as navigable surroundings but also as visual displays with forms that have distinctive angular shapes. Because children come to understand the symbolic functions of pictures, models, and maps over the first 4 years of life, children can begin to add angle information to their representations of large-scale layouts. Second, through their experience with physical and mental rotation, children and adults may become able to treat small-scale objects and forms not only as visual displays with distinctive shapes but as layouts that can be explored from different perspectives, by means of navigation systems that allow for stable representations of the distinction between leftward and rightward directions (Spelke et al. 2010, p. 878-879).

Despite the fact that our geometric intuitions are hardwired in core cognitive systems that we share with other animals, human children learn to represent fundamental Euclidean 
properties (i.e., distance, angle, and direction) and their relationships in a unique way. Thanks to experience with artifacts, both kinds of geometric processing, i.e., layout and object geometry, can be extended to new domains of cognition. Furthermore, as Spelke and colleagues (2010) claim, artifacts simultaneously facilitate the development of "geometric concepts that are more abstract and general than the concepts provided by their core systems." (p. 879).

Although the core systems account gives us a deep insight (also in the evolutionary sense) into the neurocognitive foundations of processing of geometric properties (and thus fulfills D1), and emphasizes the role of artifacts in setting up a necessary representation system (that goes beyond core foundations) by individuals (and thus fulfills D2), it says nothing about the emergence of the key epistemic values of geometry, i.e., generality and necessity of its arguments, so it fails to satisfy (D3) and (D4). Furthermore, Spelke's account does not show enough of the way that cognitive artifacts, i.e. technical language and diagrams, have shaped Euclidean geometry and set "the course" of actual mathematical practices. Thus, to fulfill the remaining desiderata, we need to go back to the time when European mathematics began to emerge. We do not mean here, however, the chronological history of mathematics but rather the "cognitive history" of geometric practices (Netz 2003; see also Ferreirós and García-Pérez 2018). As we will show, this cognitive history is also still incomplete in its treatment of inference operations on cognitive artifacts.

\section{Case Study: Euclid's Elements}

The construction of an equilateral triangle on a finite straight-line is the very first proposition of Euclid's Elements that appears in the Book 1, immediately after the presentation of definitions, postulates, and common notions. The structure of the argument is following:

To construct an equilateral triangle on a given finite straight-line.

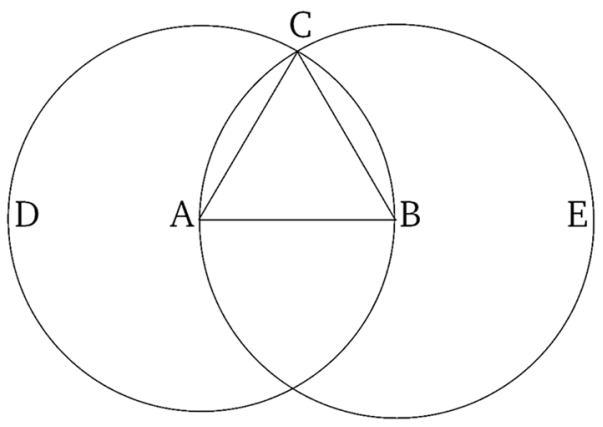

Let $A B$ be the given finite straight-line.

So it is required to construct an equilateral triangle on the straight-line $A B$.

Let the circle $B C D$ with center $A$ and radius $A B$ have been drawn [Postulate 3], and again let the circle $A C E$ with center $B$ and radius $B A$ have been drawn [Postulate 3]. And let the straight-lines $C A$ and $C B$ have been joined from the point $C$, where the circles cut one another, to the points $A$ and $B$ (respectively) [Postulate 1]. 
And since the point $A$ is the center of the circle $C D B, A C$ is equal to $A B$ [Definition 1.15]. Again, since the point $B$ is the center of the circle $C A E, B C$ is equal to $B A$ [Definition 1.15]. But $C A$ was also shown (to be) equal to $A B$. Thus, $C A$ and $C B$ are each equal to $A B$. But things equal to the same thing are also equal to one another [Common Notion 1]. Thus, $C A$ is also equal to $C B$. Thus, the three (straight-lines) $C A, A B$, and $B C$ are equal to one another.

Thus, the triangle $A B C$ is equilateral, and has been constructed on the given finite straight-line $A B$. (Which is) the very thing it was required to do (Fitzpatrick 2008).

At first glance, we see that Proposition 1-just like the rest of the mathematical treatise by Euclid-is constituted by two kinds of symbols: diagrams and textual units. Although one will not find any mathematical symbols in the modern sense in Euclid's masterpiece, the Greek diagram is not a mere auxiliary drawing, and the text (analogously to other Greek mathematical treatises such as Archimedes' Spiral lines or Pappus' Collectio) is not merely a free expression of ordinary language. It is even indicated by the fact that diagrams and words are not independent of each other, but they are connected with each other through letters. Despite the fact that geometric discourse has emerged from common drawings and linguistic practices, and it is based on our ordinary visuo-spatial resources and conceptual capacities, diagrammatic and textual units should be considered as instances of the usage of technical symbols or cultural artifacts (Netz 2003).

Before we analyze the role of these artifacts in geometric discourse, we should note that references to one definition, one common notion, and two postulates were introduced in brackets. The definition 1.15 reads that "A circle is a plane figure contained by a single line [which is called a circumference] (such that) all the straight-lines radiating towards [the circumference] from one point amongst those lying inside the figure are equal."; Common Notion 1-“Things equal to the same thing are also equal to one another."; and postulates sound as following: " 1 . Let it have been postulated to draw a straight-line from any point to any point."; "3. And to draw a circle with any center and radius" (again, we use the translation of Euclid's Elements by Fitzpatrick 2008).

Although Elements are the first grand-scale application of the axiomatic-deductive method to mathematics (Russo 2004), the passage quoted above is not a restricted proof in the contemporary formal sense (Detlefsen 2005; Marciszewski and Murawski 1995). Other arguments of Euclid are also based not only on the results of previous steps, postulates or common notions, but they refer to hidden assumptions (Hilbert 1950; Pasch 1912; Proclus 1970). Euclid explicitly claims, for instance, that "the circles cut one another." This fact is not a logical consequence of the postulates or the common notions, but can be seen in the diagram. Further, Euclid determines that "three (straight-lines) $C A, A B$, and $B C$ are equal to one another," and concludes that "the triangle $A B C$ is equilateral." There is no postulate (or common notion) asserting that these straight-lines lie on the same plane. One can, however, see this fact in the diagram. Furthermore, there is another hidden assumption in the quoted proof. Suppose that straight-lines $A C$ and $B C$ have a common segment. Thus, the circles with the circumcenters $A$ and $B$ do not have to cut one another in point $C$, but they can cut it in any other point lying on the common straight-line. Again, starting from 
Euclid's postulate-set we cannot prove that no two distinct straight lines have a common segment - it becomes clear and distinct if we look at the diagram. ${ }^{5}$

The presence of hidden assumptions, however, does not mean that Euclid's argument is unsound. The typical Greek proof is not a simple outcome of mechanical manipulations of meaningless symbols, which starts from axioms and is carried out according to necessity-preserving rules ( $\operatorname{Rav} 2007$ ). Recognizing its correctness requires the consideration of diagrammatic components (Magnani 2001; Netz 1998). In other words, diagrams have the constraining role in reasoning: they disambiguate the argument. This contributes to the stability of cognitive practices, rather than to the realization that the argument is ambiguous, and therefore not really compelling, as radical constructivists could argue. Quite the contrary, just because, by following the same procedure, one can attain the same result, the proof establishes the inter-subjective validity of mathematical truth.

Since the structure of derivation is intuitive and inspectable, Euclidean arguments have compelling power. In addition to their necessity, they are considered general. Proclus (1970) states this fact explicitly as follows:

... mathematicians are accustomed to draw what is in a way a double conclusion. For when they have shown something to be true of the given figure, they infer that it is true in general, going from the particular to the universal conclusion. Because they do not make use of the particular qualities of the subjects but draw the angle or the straight line in order to place what is given before our eyes, they consider that what they infer about the given angle or straight line can be identically asserted for every similar case. They pass therefore to the universal conclusion in order that we may not suppose that the result is confined to the particular instance (p. 207).

Historians of science agree that Greeks followed deductive proofs at first in the history and that "the power of proof" has driven further development of mathematics (Hartshorne 2007; Merzbach and Boyer 2011; Russo 2004; Szabó 1978). We have, however, to identify the features of geometric discourse leading to the cognitive possibility of a deductive proof. Thus, in the next section we will carefully investigate, by referring mainly to findings of Reviel Netz, the roles and functions of cognitive artifacts of Greek geometry. We will however point out that in his account, it remains unclear what cognitive operations on diagrams actually warrant the compelling power and generality. While geometric proofs obviously did not rely on formal logical rules, the reasoning behind them is itself still poorly understood.

\section{Cognitive Artifacts of Euclidean Geometry: Lettered Diagrams and Linguistic Formulae}

A diagram, from the Greek $\delta i \alpha ́ \gamma \rho \alpha \mu \mu \alpha$ that literally means "figure marked out by lines" (Netz 2003, p. 35), is a visual symbol, usually two-dimensional, commonly used in geometry. ${ }^{6}$ According to the widespread view, Greek mathematicians used a stick to draw

\footnotetext{
5 Tracking down the hidden assumptions or "further propositions" in Euclid's Elements is nothing new, since Epicurean philosopher, Zeno of Sidon, has already done it. The last example comes from his work (Vlastos 1995).

${ }^{6}$ Roles of diagrams in reasoning has been discussed so far in numerous studies. Most of them refer explicitly to geometry (Magnani 2013; Manders 2008; Miller 2007; Mueller 1981; Mumma 2009; Panza 2012),
} 
diagrams in properly prepared (wetted and tamped) sand. They also used dusted surfaces, and portable wood or wax tablets. As opposed to the contemporary blackboard, these media were incapable of being easily erased and corrected. Although Greek mathematicians used rulers and compasses, their constructions were imperfect and schematic, and thus, their reception, as Netz (2003) noted, "required some imagination" (p. 19).

In most cases, Greek mathematicians started geometric constructions from a diagram (as a supplement to an oral argument), then the letters were inserted, and finally, the constructions were complemented with verbal formulae. Hence, the first function of a diagram is to spatially organize an argument, and to provide the scaffolding for a written part of the geometric discourse (Netz 1998, 2003). At the same time, a diagram enables an initial orientation in a problem by launching the reader's imagination (Giaquinto 2007; Magnani 2001). A diagram is not, however, only a cognitive artifact that is handy for an individual reader. Instead, since a diagram exists in a public space, and it is a manipulable symbol, it allows mathematicians to collectively solve problems in real time. Moreover, a diagramat least in principle - can be passed on and further developed by next generations of mathematicians. In other words, a diagram delivers an external representational support to mathematical thinking both in shorter and longer time scales (Tylén et al. 2014). The role of diagrams does not end, however, on organizing an argument and facilitation of understanding of argument expressed orally. Prior to the analysis of further functions of diagrams, it is necessary to indicate their relationship to the text.

Although Babylonian, Egyptian, and Chinese mathematicians all used diagrams before the Greeks, marking them with letters is a uniquely Greek invention (Cajori 1928, p. 376). ${ }^{7}$ The letters make the Greek diagram something more than an auxiliary drawing or pedagogical assistance. Each diagram presented in Euclid's Elements is, according to Netz (2003), a combination of two kinds of entities, i.e., the continuous ("the figure marked out by the lines") and the discrete (the letters). At the same time, it combines visual resources and manageable models. The basic function of letters is to bind together "the figure marked out by the lines" and strings of words surrounding it-letters present in the textual part of an argument constitute references to the specific points of the diagram. In this way, as Netz (ibid.) says, "a linguistic, discrete net is cast over the quasi-continuous visual experience" (p. 165).

Many diagrams cannot be reconstructed from a text directly, thus they are irreducible units of geometric discourse. About half of all letters that appeared in textual parts of Euclid's Elements and other treatises by Greek mathematicians are undetermined, in the sense that the sole text is insufficient to establish reference of the letters to the points. Hence, the function of the diagram is the determination of geometric objects. Thanks to diagrams, objects acquire their reference, and thus geometric assertions acquire their truthvalue. Thus, according to Netz, "part of the content is supplied by the diagram, and not solely by the text" (p. 34). The diagram is an obligatory element of Greek deductive practices since, as we have seen in the previous section, assertions are derived from both the text and the diagram. In other words, the diagram is a full-blooded component of geometric

Footnote 6 (continued)

but there are also advanced studies on diagrams in non-mathematical domains (Abrahamsen and Bechtel 2015; Bauer and Johnson-Laird 1993; Tylén et al. 2014).

7 It should be noted that the Babylonian-Egyptian mathematics, in contrast to Greek mathematics, did not formulate general theorems. Although this feature depends primarily on the absence of verbal definitions, diagrammatic practices of Babylonian and Egyptian mathematicians also seem to be insufficient. 
arguments (see also Avigad et al. 2009). Now, let us turn to another cognitive artifact of Greek mathematics: the technical language.

The language of geometry consists of a small manageable lexicon, which covers, according to Netz's (2003) approximation, no more than 200 words, and is organized by "the one-concept-one-word" principle. Thanks to this principle, synonyms and homonyms are quite rare, which makes the mathematical language sharper and more precise than ordinary language. (The technical language of geometry is also unique, compared to other Greek scientific discourses, e.g. anatomical, ibid, pp. 121ff). Furthermore, words belonging to the geometric lexicon do not create any arbitrary combinations; instead, a relatively small number of (about 200) fixed strings of words are used repetitively among authors. Netz $(1999,2003)$ has dubbed these strings linguistic formulae (or formulae, in brief), at the same time directing that they should be considered the second fundamental artifact (or cognitive tool, in his terminology) of Greek mathematics.

Just like in the oral tradition of Greek poetry, in which fixed formulae constitute tools that "...explain the cognitive possibility of poetry" (Netz 1999, p. 149) in the absence of writing skills, in the case of geometry, they may contribute to an explanation of the cognitive possibility of deductive practices in Greek geometry in the absence of modern mathematical symbolism. In both cases, the language, based on fixed and repetitive formulae, is an artifact that enhances human cognitive abilities. Regarding the cultural emergence of this artifact, as Netz (ibid.) explicitly claims, geometric categories are not determined by the Greek language itself, but its specific use, i.e., "ruthless limitation of language to a small set of some very definite hierarchical relations" (ibid., p. 163) enabled the further development of geometry.

Netz $(1999,2003)$ found that almost all preserved Greek mathematical writings were formulaic. ${ }^{8}$ From the structural point of view, formulae are both holistic units of mathematical discourse and objects made of smaller constituents. Furthermore, formulae-in principle_-are transformable into other formulae. Thus, according to Netz (1999), formulaic expressions have a generative structure "in the sense that new expressions may be combined by fitting new formulae in the allowed slots" (p. 156). In consequence, “...there is a system of rules for the production of recognizably formulaic structures" (ibid.). In other words, the fixed system of geometric formulae appears as a kind of a generative grammar or structured system of recurrences, which makes computational operations available.

Therefore, the development of technical language (and not just vocabulary) leads to the stabilization of the cognitive practice. By removing inherent ambiguity of natural language, technical language constrains reasoning practices, which warrants that the same formulae will lead to the same conclusion, given the same premises. However, as we stressed in the preceding section, the technical discourse of Euclid's Elements remains ambiguous without lettered diagrams, and conclusions follow only when one sees the diagrams. In other words, it is the combination of the two components that contributes to the cognitive stability of Greek geometry, and this stability can contribute to the necessity of a geometric proof: the same result is achieved every time the operations are performed.

\footnotetext{
${ }^{8}$ He shows that the formulae in Euclid's Elements and other Greek mathematical treatises can be grouped into several hierarchic kinds, namely, object formulae, construction formulae, predicate formulae, argumentation formulae, and second-order formulae (Netz 1999, 2003).
} 


\section{Drawing Inferences Using Diagrams: in Search of Operations}

The cognitive history of Euclidean geometry as presented by Netz lacks, however, a substantial account of geometric operations that are performed using these cognitive artifacts, and thus does not satisfy (D5). Although linguistic formulae, supplemented by a diagram, reflect deductive steps leading to a general result in a necessary way (see the next section), it should be emphasized that this chain is only a final product of cognitive operations performed on well-formed geometric representations. The intertwined use of diagrams and technical language constrains a space of cognitive operations, but these operations are "hidden beneath" external artifacts, and cannot be perceived in terms of pure deduction. This fact makes the issue difficult to study, but some insights have been presented by Charles Sanders Peirce at the beginning of 20th century, and recently further developed by Lorenzo Magnani. Peirce has distinguished between so-called corollarial and theorematical kinds of reasoning.

While the former, "is one the truth of which will become evident simply upon attentive observation of a diagram constructed so as to represent the conditions stated in the conclusion," the latter "is one which only becomes evident after some experiment has been performed upon the diagram, such as the addition to it of parts not necessarily referred to in the statement of the conclusion" (Peirce 1903/1976, p. 419; see also idem 1902/1991). Corollarial reasoning proceeds according to well-formed rules, similar to logical rules of inference, such as modus ponens. It may be perceived as "mechanical". In contrast, theorematical one is, according to Peirce, "unmechanizable" and involves creativity in experimentation with new elements of diagrams (see Stjernfelt 2007, 2011). As we have seen previously, complete diagrams enshrined in Elements can be perceived as full-blooded components of Euclid's proofs. The diagrammatic operations involved in completing the proof to perform geometric reasoning, or finding how to perform the geometric verification by drawing parts of diagram underlying immediate inferences, have, according to Peirce, an abductive character.

As Magnani (2009, 2013) stresses, following Peirce's pioneering research, only by experimenting with diagrams one may discover what actually could be proven using a given diagram. In particular, it is far from obvious that to prove Proposition 1, which pertains to triangles, one should draw circles at all. According to Magnani, to see that a certain number of circles, positioned appropriately on the diagram, is sufficient for this proof, one has to experimentally discover, maybe by drawing a number of different diagrams, that the construction that relies on circles leads to the proof. This kind of abduction, which is theorematical reasoning, is dubbed by Magnani $(2009,2013)$ manipulative abduction because it is a fallible process of discovery of theorems via manipulation of publicly available cognitive artifacts (see also Park 2017; Rivera \& Becker 2007). However, as soon as "unmechanizable" experimentation leads to the proof, one can present the result of this abductive process as purely "mechanical" deductive reasoning. Therefore, fulfillment of (D5) arguably requires a detailed explanation of corollarial as well as theorematical operations involved in geometric cognition. 


\section{The Emergence of Epistemic Virtues of Euclidean Geometry}

Having both artifacts at hand, i.e., a lettered diagram and the technical language consisting of fixed formulae, we can briefly discuss their role in shaping the generality and necessity of Greek mathematics. In Euclid's construction of an equilateral triangle on a finite straight-line, which was introduced in Sect. 2, the diagram serves as the starting-point of the argument. By "starting points" Netz $(1998,2003)$ understands instances appearing as clear and distinct - they are necessarily true without any argument. In addition to diagrams, common notions, postulates, and other assertions (expressed textually) can also be starting points. They constitute the first kind of "the atoms of necessity." Necessity, recognized in this way, is subsequently transmitted through the "atoms" of the second kind, i.e., mathematical arguments. Notice that it is not clear what, specifically, this transmission consists of: deductive practices rely on these "atoms" but Netz fails to elucidate the notion of transmission. This is not a coincidence; understanding geometric reasoning in an evolutionarily and psychologically plausible way is still an open problem (Sloman 2002). For example, one could argue that individual mathematical capacities (traditionally called "intuition") have shaped this reasoning and underlie it. However, it is as well plausible to claim that the intuition itself has been shaped by the widespread use of the artifacts. Further research is needed in this area.

In many cases, starting points and steps are combined within a single proof. Moreover, sometimes, recognizing the necessity of an argument requires referring to other mathematical facts, for example, background knowledge can be presented explicitly in the same treatise, or requires reaching for "canonical" facts, which were absorbed by mathematicians during previous practice. In all cases, as Netz (2003) notes:

The necessity-preserving properties of Greek mathematical proofs are all reflected by their proofs, and no meta-mathematical considerations are required. As a rule, the necessity of assertions is either self-evident (as in starting-points) or dependent on nothing beyond the immediate background. ... The structure of derivation is fully explicit. Immediate inspection is possible; this, and no meta-mathematical consideration, is the key to necessity. ... Greek mathematical proofs offer nowhere to hide. Everything is inspectable (p. 215).

Euclidean proofs, besides being necessary, are general. Although each proof concerns some specific objects, and utilizes concrete resources (lettered diagrams and linguistic formulae), it proves general results. In contrast to necessity, as Netz (ibid.) says “...there are no atoms of generality, there are no 'elements' in the proof which carry that proof's generality ... Generality exists only on a more global plane" (p. 240). Prior to presenting such a "more global plane," it should be noted that Greek mathematicians did not use induction or argumentation though isomorphism. They did not know meta-mathematics, and reduction was their primary argumentative device. Furthermore, on the linguistic level, they did not use the formula "and therefore this has been proved generally" (ibid., p. 242). The term

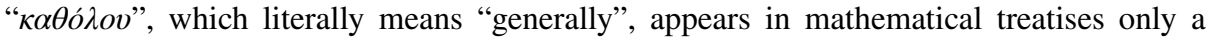
few times (e.g., in Euclid's Elements, VI.20, it refers to perfect induction, i.e., situation, in which the result valid for triangles is also valid for all polygons; cf. ibid. p. 242ff). The term "öpoıs," which means "similarly," is more important for the generality of geometric

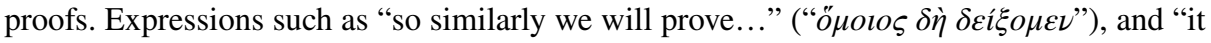

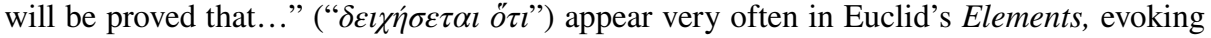
assertions which are not proved directly (ibid.). It does not mean that a particular argument 
magically "extends" to other instances. Such formulae rather deliver the disposition for the possibility of proving similar assertions in a very similar way again and again (the important point is that "the very similar way" means a very similar sequence of words).

The repeatability constitutes the main source of generality of geometric proof, and results not only from a technical language constituted by a relatively small number of fixed formulae, but also from the fixed structure of the proposition (ibid., p. 252ff). Each proposition of Euclid's Elements has a structure, which includes the following component parts (the relevant chunks of Proposition 1 of the Book 1 are shown below in the brackets): General Enunciation ("To construct an equilateral triangle on a given finite straight-line"), Particular Setting-out ("Let AB be the given finite straight-line."), Particular Definition of Goal ("So it is required to construct an equilateral triangle on the straight-line AB."), Added Construction ("Let the circle BCD with center A and radius AB have been drawn, and again let the circle ACE with center B and radius BA have been drawn. And let the straight-lines $\mathrm{CA}$ and $\mathrm{CB}$ have been joined from the point $\mathrm{C}$, where the circles cut one another, to the points A and B."), Proof (And since the point A is the center of the circle $\mathrm{CDB}, \mathrm{AC}$ is equal to $\mathrm{AB}$ [Definition 1.15]. Again, since the point $\mathrm{B}$ is the center of the circle $\mathrm{CAE}, \mathrm{BC}$ is equal to $\mathrm{BA}$ [Definition 1.15]. But CA was also shown (to be) equal to $\mathrm{AB}$. Thus, $\mathrm{CA}$ and $\mathrm{CB}$ are each equal to $\mathrm{AB}$. But things equal to the same thing are also equal to one another [Common Notion 1]. Thus, $\mathrm{CA}$ is also equal to CB. Thus, the three (straight-lines) $\mathrm{CA}, \mathrm{AB}$, and $\mathrm{BC}$ are equal to one another."), and finally Stated Conclusion (Thus, the triangle $\mathrm{ABC}$ is equilateral, and has been constructed on the given finite straight-line AB. (Which is) the very thing it was required to do."). The fixed structure of each proposition, which can be perceived as another cognitive artifact of Greek mathematics, facilitates the formulation of arguments and perceiving them as general.

We would like to strongly emphasize that the fixed structure of each proposition in the Elements is not the outcome of a direct agreement of "the caste of mathematicians," nor the application of scientific rigor, which would be trained by Euclid during the institutionalized training that proceeds, according to the conventional curriculum. Furthermore, according to Netz (ibid.), the whole Greek geometry was rather "an enterprise pursued by ad hoc networks of amateurish autodidacts-networks for which the written form was essential; constantly emerging and disappearing, hardly ever obtaining any institutional foothold." (p. 291-292). In this sense, Euclid's invention, which favors generality, is built on the results of the laborious practices of several generations of mathematicians. We do not mean, however, specific mathematical results achieved by Euclid's individual predecessors, but rather the fact that these results were continually driven by cognitive artifacts, i.e., lettered diagrams and technical language consisted of fixed formulae. Thus, according to Netz (ibid.), "the simplification of the universe, both in terms of the qualitative diagram and in terms of the small and well-regulated language, [that] makes inspection of the entire universe possible" (p. 266) is a necessary step toward generality.

Furthermore, although the artifacts are built on our ordinary perceptual and linguistic skills, consistent application of these artifacts enhances these skills, and contributes to building cumulative cognitive niches for further cognitive practices (Clark 2006). While Netz notices the crucial role of cognitive tools in geometry, he does not offer a specific account of how cumulation of artifacts has shaped the development of geometry and how, specifically, it contributes to geometric cognition by constraining the currently poor-understood capacity for geometric inference. Again (D5) is not yet satisfied here.

Cognitive artifacts, therefore, play a crucial enabling role in understanding the necessity and generality of a mathematical proof. It is not (only) the intuition of a single individual, as Platonic tradition would have it, nor power relationships that underwrite the validity of 
the proof; it is the replicability of the result by following the same procedure. By constraining the space of legitimate cognitive operations, and excluding, for example, interpretations of a proof that are incompatible with lettered diagrams, cognitive artifacts contribute to the inter-subjectivity of geometry as science, which then does not require any strict institutional infrastructure to remain resilient to disproval.

\section{How to Constrain Epistemology Without Ontology}

According to Netz (2003), "each geometrical proposition sets up its own universe-which is its diagram." (p. 32) He claims that diagrams, in virtue of their inter-subjective stability, substitute mathematical ontology, in the sense that one does not need to know what diagrams refer to in order to use diagrams in mathematical reasoning:

Proofs were done at an object-level, other questions being pushed aside. One went directly to diagrams, did the dirty work, and, when asked what the ontology behind it was, one mumbled something about the weather and went back to work. This is not meant as a sociological picture, of course. I am speaking not of the mathematician, but of the mathematical proposition. And this proposition acts in complete isolation, hermetically sealed off from any second-order discourse. There is a certain single-mindedness about Greek mathematics, a deliberate choice to do mathematics and nothing else. That this was at all possible is partly explicable through the role of the diagram, which acted, effectively, as a substitute for ontology (Ibid., p. 57).

In essence, what Netz seems to imply here is that operations on physical instances of cognitive artifacts are sufficient to do mathematics, and no semantics of these artifacts as public representations is involved. While there is a sense in which one does not need to know the ontology of geometry, in order to prove theorems using lettered diagrams and a restricted technical language, Netz suggests somewhat too much. We claim that actually, the use of these cognitive artifacts is ontologically neutral, while at the same time, it is not epistemologically neutral. In other words, these artifacts constrain the available rational reasoning moves in the proof, but they do not constrain ontological options at all.

Cognitive artifacts can be used to produce the same results in a stable manner as far as cognitive operations remain stable. The stability of deductive practices in Euclidean geometry is warranted by the distributed cognitive practice of their use. Users who interpret these artifacts in a Platonic vein as models of the ideal mathematical entities, or in the constructive vein as producing fleeting mathematical entities, still share the same practice. By itself, the practice remains thus ontologically neutral.

Further, Netz's claims about ontology do not seem to be properly substantiated by the historical knowledge of Greek geometry. There is no textual evidence that geometers actually refrained from thinking about, say, rectangular physical things when they reasoned about rectangles (as Aristotelian tradition would have it). Indeed, in ancient Greece, geometry was not merely a matter of mathematical discourse, but it had a technological application in architecture (Leonardis 2016) as well, so at least some geometers could easily adopt a roughly Aristotelian view on geometric objects. Moreover, geometric proofs might have their roots in peg-and-cord constructions (Seidenberg 1959), which could also inspire a realistic attitude towards geometric objects. 
We also know well that ontological debates existed in ancient times: the constructive school of Menaechmus would claim that geometric objects are created-they interpret Euclid literally, to say that we construct an equilateral triangle, while the school of Speusippus, the follower of Plato, claims that such objects exist eternally (Bowen 1983). It is simply not clear why then Greek geometers would want to replace the ontology they debated about with lettered diagrams and technical language. Netz (2003) seems to be aware of this fact, when he stresses that he speaks "not of the mathematician, but of the mathematical proposition" (p. 57). Particular mathematicians might have some ontological views, while the proposition did not. This is a metaphorical phrase which is probably intended to say that mathematical propositions by themselves do not settle ontological issues of mathematical objects. But it is not the same as claiming that diagrams serve as a substitute for ontology, which is a stronger claim, whose meaning we take as: Greek geometry proceeds in a splendid isolation from ontology just like game of dice. It does not matter for the game of dice what symbols on dice mean. Similarly, Netz seems to suggest that it does not matter what Euclidean proofs mean outside the practice of geometry.

But Greek geometry was not considered as mere game with external props such as dice or Five Lines, popular at the time. We remain, therefore, skeptical of the ontological substitute role that Netz ascribes to diagrams. Lettered diagrams and technical language make it possible to completely justify mathematical propositions. They are, therefore, epistemologically isolated from issues of what exists in reality and what does not. For example, even if all cognitive artifacts depicting lines were not perfect (and somewhat jarred), and no perfect lines would exist in the physical reality, the proofs would remain sound because deductive operations in geometry are only sensitive to a selected (and socially shared) subset of properties of cognitive artifacts. In this sense, the epistemological practice of justification is completely determined and constrained by these artifacts. But ontology is not because one can remain a mathematical realist in the Platonic tradition, or follow constructivism, or adhere to an Aristotelian kind of realism. The realist attitude, in general, permeates the mathematical practice in Greece, without ever clashing with the mathematical content of proofs just because they do not substitute for ontology; they remain totally silent about it. ${ }^{9}$

Thus, we claim that the generality and necessity of the geometric proof are attained in an ontologically-neutral fashion. Lettered diagrams, along with linguistic instructions, merely constrain the reasoning operations that can be performed on them.

\section{Conclusions}

The role of cognitive artifacts in the historical development of geometry, as enshrined in Euclid's unique achievement and other Greek treatises on geometry, suggests that mathematical practices were shaped by enculturation and loose social networks of Greek autodidacts. However, the social underpinnings of this practice have remained largely implicit, and are, obviously, not mentioned in Euclid's text. Moreover, the understanding of deduction in Elements has also evolved over time, so we do not mean to suggest that the role of artifacts is fixed forever by its beginnings. The social practice of repeating the proof was enabled by the way deduction was understood by Greek geometers. It is essentially a public

\footnotetext{
9 Similarly, in the following centuries, radically nominalist followers of Roscelin of Compiègne (see Kluge 1976) and Hobbes (see Bird 1996) could still engage in the geometric practice that remained neutral regarding the ontological issues of geometry.
} 
use of a cognitive artifact to drive inferences, and these inferences are strongly constrained by diagrams and technical language, in order to lead to the same conclusion.

At the same time, in spite of varying interpretations of deduction, the roughly invariant aspect of the proof procedures, brought to the fore by the enculturation approach to mathematical practice, is that it is a public, replicable procedure. Proofs are also cognitive artifacts, hence, when they grow too complex to be humanly understood, they may incite skepticism, as was the case of the four-color theorem (Bassler 2006; Tymoczko 1979).

The immense role of cognitive artifacts in the mathematical practice, from lettered diagrams, technical languages, and notations to computational devices, suggests that the epistemology of mathematics, the pinnacle of human intellectual activity, must also account for social and cultural factors. These public devices are what makes mathematics scientific and inter-subjectively justifiable, and we applaud their further study by the cognitive science of mathematics that goes beyond the recognizing "hardwired" cognitive abilities that are necessary to doing Euclidean geometry (D1).

In the study of the cognitive bases of mathematics, there is a crucial role of material culture, both in the development of individual geometric capacities of human beings, and in the development of mathematical procedures in general. As demonstrated by Spelke and colleagues (2010), artifacts such as maps and scale-models influence the development of abstract geometric concepts in children, that overcome the limits of core systems (D2). But artifacts also confer another important virtue on the mathematical proof procedures, by licensing their replicability, and therefore, their epistemic credibility and compelling power, while leaving ontological issues open. We have repeatedly stressed the necessity and generality of the mathematical proof that is warranted, rather than undermined, by the use of cognitive artifacts (D3) and (D4).

However, it is still not clear whether core systems rely on the same reasoning mechanisms as the distributed practice of Greek geometry, which means that (D5) is not yet fulfilled. While there are theories that suggest that mathematical reasoning, in general, relies on perceptual capacities and external notations (Goldstone et al. 2017; Landy et al. 2014), there are no worked-out accounts of reasoning using geometric symbols. One could suspect that they also are performed, as Goldstone et al. and Landy et al. suggest, just like logical reasoning, which, according to them, relies on perceptual and sensorimotor systems. External cognitive artifacts would only make the deductive operations more stable as they would no longer rely only on imagery. Another possibility is that there are two different systems of operations of reasoning, which would be consistent with the general functional separation of the core systems and the more enculturated part of mathematical cognition. In general, the challenge is to provide an account that would be both evolutionarily and psychologically realistic, which means that given some capacities for geometric reasoning in non-human animals, it cannot be based on the linguistic account of inference.

In this paper, we looked at the development of Euclidean geometry in terms of practices involving cognitive artifacts. We proposed a list of desiderata that the future theory of geometric cognition should satisfy and noted challenges that this theory faces. We have also found that cognitive artifacts completely constrain the reasoning (the epistemology of the proof) without deciding the ontology of the mathematical discourse.

The development of concepts and proof procedures are just two important uses of cognitive artifacts. Although the fact that the physical environment offers cues that facilitate the problem solving by cognitive agents unbeknownst to them has been recognized in psychology well (T. D. Wilson and Nisbett 1977), current knowledge about geometric discovery still relies on anecdotal evidence or verbal self-reports of famous 
mathematicians (e.g., Hadamard 1945). In our opinion, focusing on cognitive artifacts may be fruitful also regarding this matter. Moreover, some artifacts may make the process of learning mathematics easier, which is of obvious interest to mathematical educators. Thus, attention to the enculturation of mathematical practice offers important insights to both cognitive science, education, and the philosophy of mathematics.

Acknowledgements The authors would like to thank Michael Heller, Bartosz Brożek, as well as the participants of the Philosophy of Cognitive Science Seminar at the Institute of Philosophy and Sociology of the Polish Academy of Sciences for their helpful critical comments to the previous version of the manuscript. We are also grateful to the Anonymous Reviewers for their valuable remarks.

Funding Preparation of this manuscript was supported by research Grants 2015/19/B/HS1/03310 (PI: MH) and 2014/14/E/HS1/00803 (PI: MM) from the National Science Centre, Poland. MH is supported also by the START Scholarship funded by the Foundation for Polish Science (FNP).

Open Access This article is distributed under the terms of the Creative Commons Attribution 4.0 International License (http://creativecommons.org/licenses/by/4.0/), which permits unrestricted use, distribution, and reproduction in any medium, provided you give appropriate credit to the original author(s) and the source, provide a link to the Creative Commons license, and indicate if changes were made.

\section{References}

Abrahamsen, A., \& Bechtel, W. (2015). Diagrams as tools for scientific reasoning. Review of Philosophy and Psychology, 6(1), 117-131. https://doi.org/10.1007/s13164-014-0215-2.

Adams, J., Barmby, P., \& Mesoudi, A. (Eds.). (2017). The nature and development of mathematics: Crossdiscplinary perspectives on cognition, learning and culture. New York: Routledge.

Amalric, M., Wang, L., Pica, P., Figueira, S., Sigman, M., \& Dehaene, S. (2017). The language of geometry: Fast comprehension of geometrical primitives and rules in human adults and preschoolers. PLoS Computational Biology, 13(1), e1005273. https://doi.org/10.1371/journal.pcbi.1005273.

Avigad, J., Dean, E., \& Mumma, J. (2009). A formal system for Euclid's Elements. Review of Symbolic Logic, 2(4), 700-768. https://doi.org/10.1017/S1755020309990098.

Bassler, O. B. (2006). The surveyability of mathematical proof: A historical perspective. Synthese, 148(1), 99-133. https://doi.org/10.1007/s11229-004-6221-7.

Battista, M. T. (2007). The development of geometric and spatial thinking. In F. K. Lester Jr (Ed.), Second handbook of research on mathematics teaching and learning (pp. 843-908). New York: Information Age Publishing. https://doi.org/10.2307/23084627.

Bauer, M. I., \& Johnson-Laird, P. N. (1993). How diagrams can improve reasoning. Psychological Science, 4(6), 372-378. https://doi.org/10.1111/j.1467-9280.1993.tb00584.x.

Bird, A. (1996). Squaring the circle: Hobbes on philosophy and geometry. Journal of the History of Ideas, 57(2), 217-231. https://doi.org/10.1353/jhi.1996.0012.

Bowen, A. C. (1983). Menaechmus versus the Platonists: Two theories of science in the early academy. Ancient philosophy, 3(1), 12-29. https://doi.org/10.5840/ancientphil19833116.

Burton, L. (1995). Moving towards a feminist epistemology of mathematics. Educational Studies in Mathematics, 28(3), 275-291. https://doi.org/10.1007/BF01274177.

Cajori, F. (1928). A history of mathematical notations (Vol. 1). London: Open Court.

Carey, S., \& Spelke, E. S. (1996). Science and core knowledge. Philosophy of Science, 63(4), 515-533. https://doi.org/10.1086/289971.

Cheng, K. (1986). A purely geometric module in the rat's spatial representation. Cognition, 23(2), 149-178. https://doi.org/10.1016/0010-0277(86)90041-7.

Cheng, K., Huttenlocher, J., \& Newcombe, N. S. (2013). 25 years of research on the use of geometry in spatial reorientation: a current theoretical perspective. Psychonomic Bulletin \& Review, 20(6), 10331054. https://doi.org/10.3758/s13423-013-0416-1.

Cheng, K., \& Newcombe, N. S. (2005). Is there a geometric module for spatial orientation? Squaring theory and evidence. Psychonomic Bulletin \& Review, 12(1), 1-23. https://doi.org/10.3758/BF03196346.

Cipora, K., Hohol, M., Nuerk, H.-C., Willmes, K., Brożek, B., Kucharzyk, B., et al. (2016). Professional mathematicians differ from controls in their spatial-numerical associations. Psychological Research, 80, 710-726. https://doi.org/10.1007/s00426-015-0677-6. 
Clark, A. (2006). Language, embodiment, and the cognitive niche. Trends in Cognitive Sciences, 10(8), 370-374. https://doi.org/10.1016/j.tics.2006.06.012.

Clements, D. H., \& Battista, M. T. (1990). The effects of Logo on Children's conceptualizations of angle and polygons. Journal for Research in Mathematics Education, 21(5), 356-371. https://doi. org/10.2307/749394.

Cohen Kadosh, R., \& Dowker, A. (Eds.). (2015). The Oxford Handbook of Numerical Cognition. Oxford: Oxford University Press.

Dehaene, S. (2011). The number sense (Revised). Oxford: Oxford University Press.

Dehaene, S., Izard, V., Pica, P., \& Spelke, E. S. (2006). Core knowledge of geometry in an Amazonian indigne group. Science, 311(5579), 381-384. https://doi.org/10.1126/science.1121739.

Derdikman, D., \& Moser, E. I. (2010). A manifold of spatial maps in the brain. Trends in Cognitive Sciences, 14(12), 561-569. https://doi.org/10.1016/j.tics.2010.09.004.

Detlefsen, M. (2005). Formalism. In S. Shapiro (Ed.), The Oxford handbook of philosophy of mathematics and logic (pp. 236-317). Oxford: Oxford University Press.

Dilks, D. D., Julian, J. B., Paunov, A. M., \& Kanwisher, N. (2013). The occipital place area is causally and selectively involved in scene perception. The Journal of Neuroscience, 33(4), 1331-1336. https://doi. org/10.1523/JNEUROSCI.4081-12.2013.

Dillon, M. R., Huang, Y., \& Spelke, E. S. (2013). Core foundations of abstract geometry. Proceedings of the National Academy of Sciences, 110(35), 14191-14195. https://doi.org/10.1073/pnas.1312640110 /-/DCSupplemental.

Dillon, M. R., Persichetti, A. S., Spelke, E. S., \& Dilks, D. D. (2017). Places in the brain: Bridging layout and object geometry in scene-selective cortex. Cerebral Cortex. https://doi.org/10.1093/cercor/bhx13 9.

Feigenson, L., Dehaene, S., \& Spelke, E. S. (2004). Core systems of number. Trends in Cognitive Sciences, 8(7), 307-314. https://doi.org/10.1016/j.tics.2004.05.002.

Ferreirós, J., \& García-Pérez, M. J. (2018). ¿ « Natural » y « euclidiana » ?: Reflexiones sobre la geométrica práctica y sus raíces cognitivas. Theoria. Revista de Teoría, Historia y Fundamentos de la Ciencia, $33(2), 325-344$.

Fitzpatrick, R. (Ed.). (2008). Euclid's Elements of geometry. from Euclidis Elementa by I. L. Heiberg (1883). Retrieved from http://farside.ph.utexas.edu/Books/Euclid/Elements.pdf. Accessed 15 Sept 2018.

Fodor, J. A. (1983). The modularity of mind. Cambridge: The MIT Press.

Gallistel, C. (1990). The organization of learning. Cambridge: The MIT Press.

Giaquinto, M. (2007). Visual thinking in mathematics. Oxford: Oxford University Press.

Goldstone, R. L., \& Janssen, M. A. (2005). Computational models of collective behavior. Trends in Cognitive Sciences, 9(9), 424-430. https://doi.org/10.1016/j.tics.2005.07.009.

Goldstone, R. L., Marghetis, T., Weitnauer, E., Ottmar, E. R., \& Landy, D. (2017). Adapting perception, action, and technology for mathematical reasoning. Current Directions in Psychological Science, 26(5), 434-441. https://doi.org/10.1177/0963721417704888.

Gouteux, S., \& Spelke, E. S. (2001). Children's use of geometry and landmarks to reorient in an open space. Cognition, 81(2), 119-148. https://doi.org/10.1016/S0010-0277(01)00128-7.

Grill-Spector, K., Golarai, G., \& Gabrieli, J. (2008). Developmental neuroimaging of the human ventral visual cortex. Trends in Cognitive Sciences, 12(4), 152-162. https://doi.org/10.1016/j.tics.2008.01.009.

Gureckis, T. M., \& Goldstone, R. L. (2006). Thinking in groups. Pragmatics \& Cognition, 14(2), $293-311$. https://doi.org/10.1075/pc.14.2.10gur.

Hadamard, J. (1945). An essay on the psychology of invention in the mathematical field. New York: Dover Publications.

Hartshorne, R. (2007). Geometry: Euclid and beyond. New York: Springer.

Henik, A. (Ed.). (2016). Continuous issues in numerical cognition. London: Academic Press.

Hermer, L., \& Spelke, E. S. (1994). A geometric process for spatial orientation in young children. Nature, 370(3), 57-59. https://doi.org/10.1016/S0010-0277(96)00714-7.

Hilbert, D. (1950). Foundations of geometry. (E. J. Townsend, Trans.). LaSalle: The Open Court Publishing Company.

Hohol, M., Baran, B., Krzyżowski, M., \& Francikowski, J. (2017a). Does spatial navigation have a blindspot? Visiocentrism is not enough to explain the navigational behavior comprehensively. Frontiers in Behavioral Neuroscience, 11, 154. https://doi.org/10.3389/fnbeh.2017.00154.

Hohol, M., Cipora, K., Willmes, K., \& Nuerk, H.-C. (2017b). Bringing back the balance: domain-general processes are also important in numerical cognition. Frontiers in Psychology, 8, 499. https://doi. org/10.3389/fpsyg.2017.00499.

Horst, S. (2016). Cognitive pluralism. Cambridge: MIT Press. 
Izard, V., \& Spelke, E. S. (2009). Development of sensitivity to geometry in visual forms. Human Evolution, 23(3), 213-248.

Kluge, E.-H. W. (1976). Roscelin and the medieval problem of universals. Journal of the History of Philosophy, 14(4), 405-414. https://doi.org/10.1353/hph.2008.0088.

Kourtzi, Z., \& Kanwisher, N. (2001). Representation of perceived object shape by the human Lateral Occipital Complex. Science, 293(2001), 1506-1509. https://doi.org/10.1126/science.1061133.

Lakoff, G., \& Núñez, R. E. (2000). Where mathematics comes from. New York: Basic Books.

Landau, B., \& Jackendoff, R. (1993). 'What' and 'where' in spatial language and spatial cognition. Behavioral and Brain Sciences, 16(02), 217-238. https://doi.org/10.1017/S0140525X00029733.

Landau, B., \& Lakusta, L. (2009). Spatial representation across species: geometry, language, and maps. Current Opinion in Neurobiology, 19, 12-19.

Landy, D., Allen, C., \& Zednik, C. (2014). A perceptual account of symbolic reasoning. Frontiers in Psychology, 5(275), 1-10. https://doi.org/10.3389/fpsyg.2014.00275.

Lee, S. A., \& Spelke, E. S. (2008). Children's use of geometry for reorientation. Developmental Science, 11(5), 743-749. https://doi.org/10.1111/j.1467-7687.2008.00724.x.

LeFevre, J.-A. (2016). Numerical cognition: adding it up. Canadian Journal of Experimental Psychology, 70(1), 3-11. https://doi.org/10.1037/cep0000062.

Leonardis, R. (2016). The use of geometry by ancient Greek architects. In M. M. Miles (Ed.), A companion to Greek architecture (pp. 92-104). New York: Chichester.

Magnani, L. (2001). Philosophy and geometry: Theoretical and historical issues. Dordrecht: Springer Science \& Business Media. https://doi.org/10.1007/978-94-010-9622-5.

Magnani, L. (2009). Abductive cognition: The epistemological and eco-cognitive dimensions of hypothetical reasoning. Heidelberg: Springer.

Magnani, L. (2013). Thinking through drawing. The Knowledge Engineering Review, 28(03), 303-326. https://doi.org/10.1017/S026988891300026X.

Maguire, E. A. (2001). The retrosplenial contribution to human navigation: A review of lesion and neuroimaging findings. Scandinavian Journal of Psychology, 42(3), 225-238.

Malet, A. (2012). Euclid's swan song: Euclid's Elements in early modern Europe. In P. Olmos (Ed.), Greek science in the long run (pp. 205-234). Cambridge: Cambridge Scholars Publishing.

Manders, K. (2008). The Euclidean diagram. In P. Mancosu (Ed.), The philosophy of mathematical practice (pp. 80-133). Oxford: Oxford University Press.

Marciszewski, W., \& Murawski, R. (1995). Mechanization of reasoning in a historical perspective. Amsterdam: Rodopi.

Menary, R. (2015). Mathematical cognition: A case of enculturation. In T. Metzinger \& J. M. Windt (Eds.), Open MIND (Vol. 25). Frankfurt am Main: Johannes Gutenberg Universität Mainz. https:// doi.org/10.15502/9783958570818.

Merzbach, U. C., \& Boyer, C. B. (2011). A history of mathematics (3rd ed.). Hoboken: John Wiley \& Sons.

Miller, N. (2007). Euclid and his twentieth century rivals: Diagrams in the logic of Euclidean geometry. Stanford: CSLI Publications.

Milner, A. D., \& Goodale, M. A. (2006). The visual brain in action. Oxford: Oxford University Press.

Mishkin, M., Ungerleider, L. G., \& Macko, K. A. (1983). Object vision and spatial vision: two cortical pathways. Trends in Neurosciences, 6, 414-417. https://doi.org/10.1016/0166-2236(83)90190-X.

Moser, E. I., Kropff, E., \& Moser, M.-B. (2008). Place cells, grid cells, and the brain's spatial representation system. Annual Review of Neuroscience, 31(1), 69-89. https://doi.org/10.1146/annur ev.neuro.31.061307.090723.

Moser, E. I., Moser, M.-B., \& McNaughton, B. L. (2017). Spatial representation in the hippocampal formation: a history. Nature, 20(11), 1448-1464. https://doi.org/10.1038/nn.4653.

Moyer, R. S., \& Landauer, T. K. (1967). Time required for judgements of numerical inequality. Nature, 215(5109), 1519-1520. https://doi.org/10.1038/2151519a0.

Mueller, I. (1981). Philosophy of mathematics and deductive structure in Euclid's Elements. Cambridge: The MIT Press.

Mumma, J. (2009). Proofs, pictures, and Euclid. Synthese, 175(2), 255-287. https://doi.org/10.1007/ s11229-009-9509-9.

Netz, R. (1998). Greek mathematical diagrams: Their use and their meaning. For the Learning of Mathematics, 18(3), 33-39. https://doi.org/10.2307/40248278.

Netz, R. (1999). Linguistic formulae as cognitive tools. Pragmatics \& Cognition, 7(1), 147-176. https:// doi.org/10.1075/pc.7.1.07net.

Netz, R. (2003). The shaping of deduction in Greek mathematics: A study in cognitive history. Cambridge: Cambridge University Press. 
Norman, D. A. (1991). Cognitive artifacts. In J. Carroll (Ed.), Designing interaction: Psychology at the human-computer interface (pp. 17-38). Cambridge: Cambridge University Press.

Núñez, R. E. (2017a). Is there really an evolved capacity for number? Trends in Cognitive Sciences, 21(6), 409-424. https://doi.org/10.1016/j.tics.2017.03.005.

Núñez, R. E. (2017b). Number-Biological enculturation beyond natural selection. Trends in Cognitive Sciences, 21(6), 404-405. https://doi.org/10.1016/j.tics.2017.03.013.

Núñez, R. E., \& Lakoff, G. (2005). The cognitive foundations of mathematics: The role of conceptual metaphor. In J. I. D. Campbell (Ed.), The handbook of mathematical cognition (pp. 109-124). New York.

O'Keffe, J., \& Nadel, L. (1978). The hippocampus as a cognitive map. Oxford: Oxford University Press.

Panza, M. (2012). The twofold role of diagrams in Euclid's plane geometry. Synthese, 186(1), 55-102. https://doi.org/10.1007/s11229-012-0074-2.

Park, W. (2017). Magnani's manipulative abduction. In L. Magnani \& T. Bertolotti (Eds.), Springer handbook of model-based science (pp. 197-218). Dordrecht: Springer.

Pasch, M. (1912). Vorlesungen über die neuere Geometrie. Leipzig: Teubner.

Peirce, C. S. (1976). Lowell lectures. Lecture 2. In C. Eisele (Ed.), The new elements of mathematics, Vol. III/1 (C. Eisele, Ed.). Hague: Mouton Publishers.

Peirce, C. S. (1991). Minute Logic. In J. Hoopes (Ed.), Peirce on signs: Writings on semiotic (pp. 213238). Chapel Hill: University of North Carolina Press.

Penrose, R. (1996). Beyond the doubting of a shadow. Psyche, 2(23), 89-129.

Persichetti, A. S., \& Dilks, D. D. (2016). Perceived egocentric distance sensitivity and invariance across scene-selective cortex. Cortex, 77, 155-163. https://doi.org/10.1016/j.cortex.2016.02.006.

Piaget, J., Inhelder, B., \& Szeminska, A. (1960). The child's conception of geometry. New York: W. W. Norton Company.

Proclus, A. (1970). Commentary on the First Book of Euclid's Elements. (G. R. Morrow, Trans.). Princeton: Princeton University Press.

Rav, Y. (2007). A critique of a formalist-mechanist version of the justification of arguments in mathematicians' proof practices. Philosophia Mathematica, 15(3), 291-320. https://doi.org/10.1093/philmat/ nkm023.

Rivera, F. D., \& Becker, J. R. (2007). Abduction-induction (generalization) processes of elementary majors on figural patterns in algebra. The Journal of Mathematical Behavior, 26(2), 140-155. https://doi. org/10.1016/j.jmathb.2007.05.001.

Russo, L. (2004). The forgotten revolution. Berlin: Springer.

Scriba, C. J., \& Schreiber, P. (2015). 5000 years of geometry: Mathematics in history and culture. Basel: Birkhäuser.

Seidenberg, A. S. S. (1959). Peg and cord in ancient Greek geometry. Scripta Mathematica, 22, 107-122.

Sloman, A. (1978). The computer revolution in philosophy: Philosophy, science and models of mind. Sussex: Harvester Press.

Sloman, A. (2002). Diagrams in mind? In M. Anderson, B. Meyer, \& P. Olivier (Eds.), Diagrammatic representation and reasoning (pp. 7-28). London: Springer-Verlag.

Spelke, E. S. (2003). What makes us smart? Core knowledge and natural language. In D. Gentner \& S. Goldin-Meadow (Eds.), Language in mind: Advances in the study of language and thought (pp. 277311). Cambridge: Bradford Book.

Spelke, E. S., Gilmore, C. K., \& McCarthy, S. (2011). Kindergarten children's sensitivity to geometry in maps. Developmental Science, 14(4), 809-821. https://doi.org/10.1111/j.1467-7687.2010.01029.x.

Spelke, E. S., \& Kinzler, K. D. (2007). Core knowledge. Developmental Science, 10(1), 89-96. https://doi. org/10.1111/j.1467-7687.2007.00569.x.

Spelke, E. S., \& Lee, S. A. (2012). Core systems of geometry in animal minds. Philosophical Transactions of the Royal Society B: Biological Sciences, 367(1603), 2784-2793. https://doi.org/10.1098/ rstb.2012.0210.

Spelke, E. S., Lee, S. A., \& Izard, V. (2010). Beyond core knowledge: Natural geometry. Cognitive Science, 34(5), 863-884. https://doi.org/10.1111/j.1551-6709.2010.01110.x.

Stjernfelt, F. (2007). Diagrammatology: An investigation on the borderlines of phenomenology, ontology, and semiotics. Dordrecht: Springer.

Stjernfelt, F. (2011). Peirce's notion of diagram experiment: Corrollarial and theorematical experiments with diagrams. In R. Heinrich, E. Nemeth, W. Pichler, \& D. Wagner (Eds.), Image and imaging in philosophy, science and the arts (Vol. II, p. 305). Frankfurt: Ontos Verlag.

Szabó, A. (1978). The beginnings of Greek mathematics. Dordrecht: Reidel Publishing.

Thinus-Blanc, C., Chabanne, V., Tomassi, L., Peruch, P., \& Vauclair, J. (2010). The encoding of geometry in various vertebrate species. In F. L. Dolins \& R. W. Mitchell (Eds.), Spatial cognition, spatial perception (pp. 99-116). Cambridge: Cambridge University Press. 
Tomassi, L., Chiandetti, C., Pecchia, T., Sovrano, V. A., \& Vallortigara, G. (2012). From natural geometry to spatial cognition. Neuroscience and Biobehavioral Reviews, 36(2), 799-824. https://doi. org/10.1016/j.neubiorev.2011.12.007.

Tylén, K., Fusaroli, R., Bjørndahl, J. S., Rączaszek-Leonardi, J., Østergaard, S., \& Stjernfelt, F. (2014). Diagrammatic reasoning: Abstraction, interaction, and insight. Pragmatics \& Cognition, 22(2), 264-283. https://doi.org/10.1075/pc.22.2.06tyl.

Tymoczko, T. (1979). The four-color problem and its philosophical significance. The Journal of Philosophy, 76(2), 57-83. https://doi.org/10.2307/2025976.

van Hiele, P. M. (1986). Structure and insight. Orlando: Academic Press.

Vlastos, G. (1995). Zeno of Sidon as a critic of Euclid. In D. W. Graham (Ed.), Studies in Greek philosophy (Vol. II, pp. 315-324)., Socrates Plato and their tradition Princeton: Princeton University Press.

Wang, R. F., \& Spelke, E. S. (2002). Human spatial representation: Insights from animals. Trends in Ecology \& Evolution, 6(9), 376-382. https://doi.org/10.1016/S1364-6613(02)01961-7.

Weir, A. A. S., Chappell, J., \& Kacelnik, A. (2002). Shaping of hooks in New Caledonian crows. Science, 297(5583), 981. https://doi.org/10.1126/science.1073433.

Wilson, R. A. (2004). Boundaries of the mind. Cambridge: Cambridge University Press.

Wilson, T. D., \& Nisbett, R. E. (1977). Telling more than we can know: Verbal reports on mental processes. Psychological Review, 84(3), 231-259. https://doi.org/10.1037/0033-295X.84.3.231.

Wołoszyn, K., \& Hohol, M. (2017). Commentary: The poverty of embodied cognition. Frontiers in Psychology, 8, 845. https://doi.org/10.3389/fpsyg.2017.00845.

Zoccolan, D., Oertelta, N., DiCarlo, J. J., \& Cox, D. D. (2009). A rodent model for the study of invariant visual object recognition. Proceedings of the National Academy of Sciences, 106(21), 8748-8875. https://doi.org/10.1073/pnas.0811583106.

Publisher's Note Springer Nature remains neutral with regard to jurisdictional claims in published maps and institutional affiliations.

Mateusz Hohol Ph.D. is assistant professor at the Copernicus Center for Interdisciplinary Studies of the Jagiellonian University in Cracow, and postdoctoral researcher at the Section of Cognitive Science at the Institute of Philosophy and Sociology of the Polish Academy of Sciences in Warsaw. He is also a member of the Philosophy of Sciences Committee of the Polish Academy of Arts and Sciences in Cracow. He authored or co-authored two book monographs and numerous peer-reviewed articles and contributed chapters as well as co-edited several collections of scientific essays. His research interests focus mainly on cognitive science/ psychology of mathematics (numerical and geometric cognition) as well as on methodological issues of cognitive (neuro)science. Currently, he is PI of the research grant "Mechanisms of geometric cognition" (2015/19/B/HS1/03310), and researcher within the grant "Cognitive science in search of unity: Unification and integration of interdisciplinary research" (2014/14/E/HS1/00803), both funded by the National Science Centre, Poland. More information at www.hohol.pl.

Marcin Miłkowski Ph.D. is associate professor in the Section for Logic and Cognitive Science at the Institute of Philosophy and Sociology, Polish Academy of Sciences. He published Explaining the Computational Mind (MIT Press 2013), awarded with the Tadeusz Kotarbiński Prize of the Section I of the Polish Academy of Sciences and the National Science Center Award for outstanding young scholars in social sciences and humanities in 2014. He was presented with Herbert A. Simon by Association for Computers in Philosophy (IACAP) for his significant contributions in the foundations of computational neuroscience (2015). Elected expert of the Committee for Philosophical Sciences (2013-2016, 2016-) of the Polish Academy of Sciences. With R. Poczobut, he edited the volume Analytic Metaphysics of Mind (in Polish, Warszawa 2008) and Companion to the Philosophy of Mind (in Polish, Kraków 2012); with K. Talmont-Kamiński Beyond Description. Naturalism and Normativity (London 2010) and Regarding the Mind, Naturally: Naturalist Approaches to the Sciences of the Mental (Newcastle upon Tyne 2013). He is now Principal Investigator of NCN SONATA BIS 5 grant "Cognitive science in search of unity: Unification and integration of interdisciplinary research" (2014/14/E/HS1/00803). Scientific interests of Prof. Miłkowski focus on philosophy of science, including philosophy of cognitive science, and philosophy of mind and information. 